DOI: $10.12731 / 2227-930 X-2016-2-41-54$

\title{
CONTROLLABLE MODEL OF MULTIMODAL TRANSPORTATION
}

Nikolaev A.B., Ivakhnenko A.A., Pashayev V.V., Tregubov P.G.

This article discusses the construction of multimodal transportation models based on controlled networks. The developed model is parameterized by statistical data on international motor transportation. It is proposed to implement cargo traffic models through mechanisms of controlled networks. At the same time the flow in the controlled network determines how the transportation of goods comes from the top of the graph (source) to another (drain) on its arcs.

Cargo movement around the selected graph arc is performed in accordance with the selected direction. Loads moved from the source to the drain are represented as the units of cargo.

Keywords: Multimodal transportation; cargo traffics; controlled networks; graphs; statistical analysis; autocorrelation; spectral concentration.

\section{Introduction}

At the present time, development of transport networks and corridors allows logistics system to choose the objects more dynamically, since they make up the transport network on a set of performance indicators in order to reduce transport costs [16].

The main objectives in this case are: the formation of more efficient routes of goods transportation on the transport network, taking into account the business constraints (objects schedule, bandwidth of facilities, the availability of facilities, integral characteristics of vehicles and motive power). Also, when choosing an effective transport 
plans of multimodal transportation system you must take into account restrictions on the haul distances of logistics network [5, 9].

Therefore, for example, the work of the international logistics centers operator can be built on the following choice principles [3, 4]:

- information on all available terminals;

- site selection for cross-docking;

- rating for transportation in the multimodal transport system;

- selection of vehicle types to assess their availability zone and adequate load capacity;

- definition of the set of available routes;

- generalized criterion selection for evaluating the effectiveness of consolidation and deconsolidation;

- formation of the vehicles control methods;

- quantitative assessment of vehicles on the basis of the availability restrictions or fixed quotas;

- problem solution of building a load in a container based on the set of restrictions and rules;

- formation of stacking pattern in the form of tier;

- identification of the set of goods on their possible compatibility and incompatibility.

Failure of some or at least one element or object from the Automated Storage \& Retrieval System (ASRS) for undetermined reasons can lead to the disruption of the supply chain in the logistics scheme of multimodal transportation $[1,2,12]$. As a result, such violations can potentially ruin the business relationships with the customer. Typically, the ASRS is very complex, so the role and characteristics of each object cannot be evaluated without the relevant models and further statistical analysis $[7,8]$.

In practice, in order to optimize the above factors you usually have to apply a variety of means to reduce the computational operations. Thus, the corresponding operations can be very cumbersome for large quantities of ASRS items or objects $[6,10]$. 


\section{Controlled network model}

Models of cargo traffics are invited to implement through the mechanisms of controlled networks (CN) (Figure 1). The flux in the $\mathrm{CN}$ determines how the transportation of goods (in general, arbitrary objects) comes from the graph vertex (source) to another (drain) on its $\operatorname{arcs}[4,5]$.

Cargo movement through the selected arc is performed in accordance with the selected direction.

Loads moved from the source to the drain are represented as the units of cargo traffic $[7,11,14]$.

\section{Sources Controlled network}

\section{Drain}

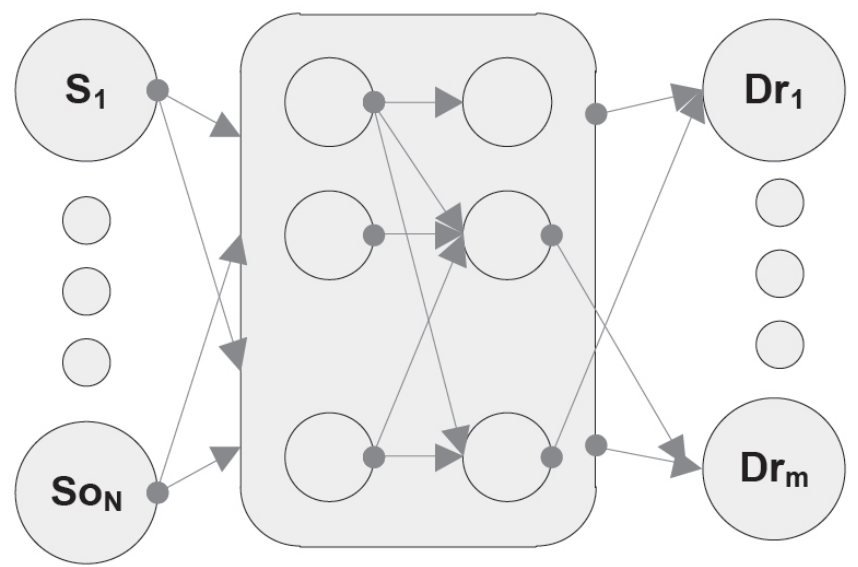

Fig. 1. Controlled network

The task of finding the maximum flow graph with any number of sources and drains was also reviewed. For this purpose, two additional peaks, the main sources and drains, are determined (Figure 2). In this case, the main source is connected to all the sources of the original $\mathrm{CN}$ $s_{1}, s_{2}, \ldots$ by arcs $\left(S, s_{1}\right),\left(S, s_{2}\right), \ldots$ It is assumed that the capacity of the new arcs, linked to the main drain and source, has no restrictions. 
Similarly, the original $\mathrm{CN}$ drains $t_{1}, t_{2}, \ldots$ are engaged with the main drain $T$. Thus, the arcs capacity $\left(t_{1}, T\right),\left(t_{2}, T\right), \ldots$, is also considered unlimited.

Thus, the flow in the expanded graph from the main drain in the main flow actually corresponds to the flow in the original graph from the set of available sources in a set of drains.

It is also possible to show that the converse proposition is happened. The maximum flow value for the extended graph (Figure 2) corresponds to the maximum value of the flow in the original graph (Figure 1). As a result, the maximum flow search procedure for ordinary graph can also be used for the flow search in the extended graph [13].

Controlled network is a set of core network and its partial finite set of subnets. Partial subnet is obtained by exclusion of several arcs of the core network. The configuration of the controlled network is the same partial subnet of the core network.

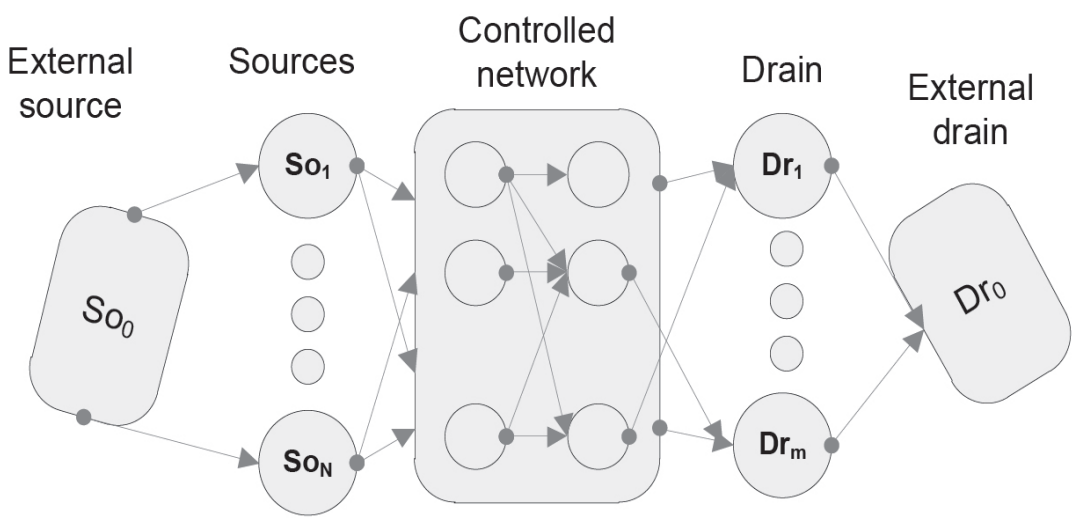

Fig. 2. Graph with multiple sources and drains

It is assumed that the flow passes through the controlled network. This control is realized by selecting the current topology or network configurations. 
In order to determine the selection rules of the network configuration the vector control is used

$$
\mathbf{u}=\left[u_{1} \ldots u_{M}\right]^{T}, \mathbf{u} \in \boldsymbol{U}=\boldsymbol{U}_{1} \times \boldsymbol{U}_{2} \times \boldsymbol{U}_{M},
$$

where $u_{i} \in \boldsymbol{U}_{\boldsymbol{i}}=\left\{0,1, \ldots, u_{i}^{+}\right\}, u_{i}^{+} \in \boldsymbol{Z}_{+,} i=\overline{1, M}, \boldsymbol{Z}_{+}$- set of positive whole numbers.

Each arc of the core network is associated with some component of the control vector.

Under certain values the components of the control vector and coupled arc with it are excluded from the core network topology that defines one of the possible configurations of $\mathrm{CN}$. One of the control vector components can be engaged with a set of $\mathrm{CN}$ arcs. Finite set of values is defined by basic $\mathrm{CN}$ for each arc, the control vector arclinked component may receive them and wherein the selected arc is not excluded from the core network.

\section{A formal description of controlled network cargo traffics}

For the formation of the control procedures in the transport and logistics network based on the $\mathrm{CN}$, the graph structure of the core network is described by an adjacency matrix

$$
\mathrm{A}=\left[a_{i j}\right], a_{i j} \in\{0,1\}, i, j=\overline{1, L},
$$

where $L-$ the number of core network nodes.

To formalize the communication elements of the control vector $\mathbf{u}=\left[u_{1} \ldots u_{M}\right]^{T}$ with the graph structure (i.e., arcs) of core network the control matrix is used

$$
\mathrm{C}=\left[c_{i j}\right], c_{i j} \in\{0,1,2, \ldots, M\}, i, j=\overline{1, L},
$$

where $c_{i j}$ - serial number of the control vector component, that is associated with the core network entity or arc, outgoing from the $i$-node to the $j$-node. In the absence of $\operatorname{arcs}$ between nodes $i$ and $j$, value will be $c_{i j}=0$, if $a_{i j}=0, i, j=\overline{1, L}$.

Control vector component takes a set of values, for the formalization of which the matrix of permitted phases is used 


$$
\mathrm{F}=\left[F_{i j}\right], F_{i j} \subseteq \boldsymbol{U}_{c_{i j}}, i, j=\overline{1, L},
$$

where $\boldsymbol{F}_{i j}$ - component of the matrix $\mathbf{F}$ is the set of values taken by the corresponding component $u_{c_{i j}}$ of the vector control $\mathbf{u}=\left[u_{1} \ldots u_{M}\right]^{T}$ for the core network arcs from $i$ to $j$, which remain in the core network graph. Therefore $\boldsymbol{F}_{i j}=\varnothing$, when $a_{i j}=0, i, j=\overline{1, L}$.

For formalized task of decreasing procedure the value of the flux vector elements (for example, for $i, 1 \leq i \leq L$ ) you should reduce the values of the components of the total throughput capacity of the arcs that originate from the node $i$, for the defined $\mathrm{CN}$ configuration.

If the value of the element $x_{i}$ is currently less than the total capacity of all output from the selected node arcs, then on the basis of the usual arithmetic subtraction you can obtain values less than zero components.

Let the controlled network be a basic graph shown in Figure 3.

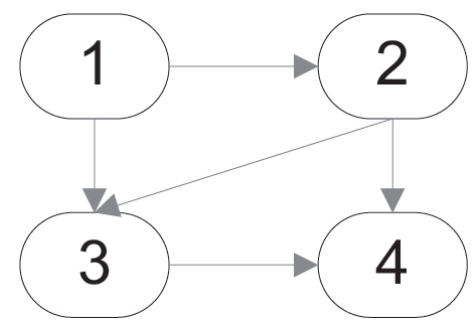

Fig. 3. Basic graph of the controlled network

Controlled network has four nodes, $L=4$, of those the node 1 is source and node 4 is drain.

As a result of the statistical parameterization necessary matrices were found. The set of controlled network configurations are shown in Figure 4.

Let's consider nine control strokes, $k=\overline{1,9}$. On each stroke we choose an arbitrary value of the control vector $\mathbf{u}=\left[u_{1} u_{2}\right]^{T}$.

The amount of flow is defined for continuous distribution matrix $\mathbf{D}$. The simulation results are represented in Table. 1. 


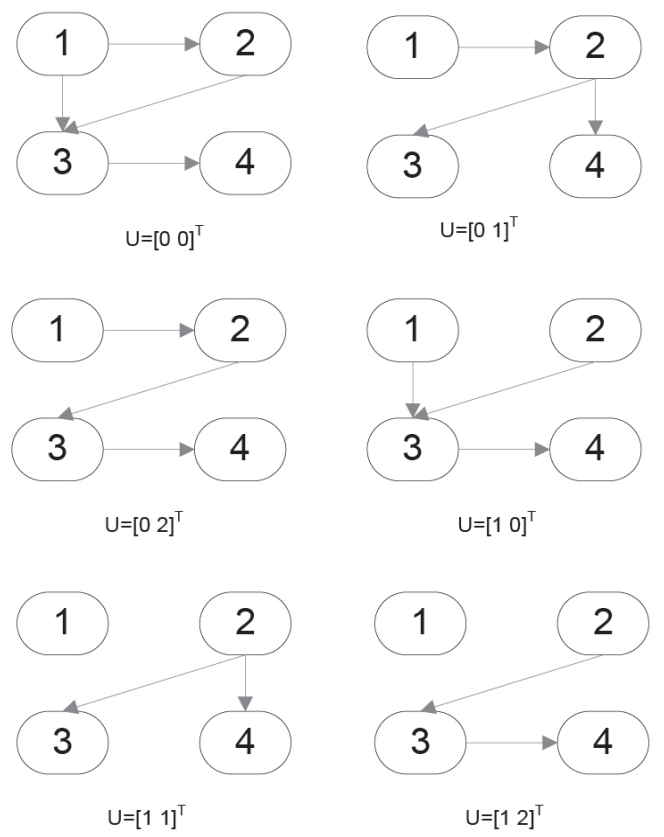

Fig. 4. Set of controlled network configurations

Simulation Results

Table 1 .

\begin{tabular}{|c|c|c|}
\hline $\mathrm{k}$ & {$\left[\begin{array}{ll}u_{1} & u_{2}\end{array}\right]^{T}$} & {$\left[\begin{array}{llll}x_{1} & x_{2} & x_{3} & x_{4}\end{array}\right]^{T}$} \\
\hline 0 & - & {$\left[\begin{array}{lllll}1000 & 0 & 0 & 0\end{array}\right]^{T}$} \\
\hline 1 & {$\left[\begin{array}{ll}0 & 0\end{array}\right]^{T}$} & {$\left[\begin{array}{lllll}973 & 12 & 15 & 0\end{array}\right]^{T}$} \\
\hline 2 & {$\left[\begin{array}{ll}0 & 1\end{array}\right]^{T}$} & {$\left[\begin{array}{lllll}9 & 61 & 12 & 21 & 6\end{array}\right]^{T}$} \\
\hline 3 & {$\left[\begin{array}{ll}0 & 1\end{array}\right]^{T}$} & {$\left[\begin{array}{llll}949 & 12 & 27 & 12\end{array}\right]^{T}$} \\
\hline 4 & {$\left[\begin{array}{ll}1 & 1\end{array}\right]^{T}$} & {$\left[\begin{array}{lllll}949 & 0 & 33 & 18\end{array}\right]^{T}$} \\
\hline 5 & {$\left[\begin{array}{ll}1 & 2\end{array}\right]^{T}$} & {$\left[\begin{array}{lllll}9 & 49 & 0 & 21 & 30\end{array}\right]^{T}$} \\
\hline 6 & {$\left[\begin{array}{ll}1 & 2\end{array}\right]^{T}$} & 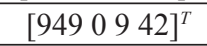 \\
\hline 7 & {$\left[\begin{array}{ll}0 & 2\end{array}\right]^{T}$} & {$\left[\begin{array}{lllll}9 & 37 & 12 & 0 & 51\end{array}\right]^{T}$} \\
\hline 8 & {$\left[\begin{array}{ll}1 & 0\end{array}\right]^{T}$} & {$\left[\begin{array}{lllll}9 & 22 & 6 & 21 & 51\end{array}\right]^{T}$} \\
\hline 9 & {$\left[\begin{array}{ll}1 & 1\end{array}\right]^{T}$} & {$\left[\begin{array}{lllll}922 & 0 & 24 & 54\end{array}\right]^{T}$} \\
\hline
\end{tabular}

In the table on the zero stroke, $k=0$, the third column gives the initial value of the flow vector, $\mathbf{x}(0)=\left[\begin{array}{lllll}1000 & 0 & 0 & 0\end{array}\right]^{T}$. 


\section{The parameterization of flows and its forecast}

For the above model of flows, the time series can be decomposed into two components - the deterministic and random $y_{\mathrm{t}}=f(t)+e_{\mathrm{t}}$. As a result of the conducted correlated data analysis ASMAP, a significant relationship between the cargo traffics (Table 2), which can be used to improve the quality of forecasts and therefore the choice of routing schemes, is showed $[45,106]$.

Table 2.

Correlation table

\begin{tabular}{|l|c|c|c|c|c|}
\hline \multirow{2}{*}{ Variable } & \multicolumn{5}{|l|}{$\begin{array}{l}\text { Correlations (ТриПоста.sta) } \\
\text { Marked correlations are significant at } p<, 05000 \\
\text { N=365 (Casewise deletion of missing data) }\end{array}$} \\
\cline { 2 - 7 } & Means & Std.Dev. & V37 & V39 & V40 \\
\hline V37 & 321,0384 & 96,59291 & 1,000000 & 0,791354 & 0,600779 \\
\hline V39 & 47,1041 & 19,10426 & 0,791354 & 1,000000 & 0,595289 \\
\hline V40 & 71,0438 & 27,33961 & 0,600779 & 0,595289 & 1,000000 \\
\hline
\end{tabular}

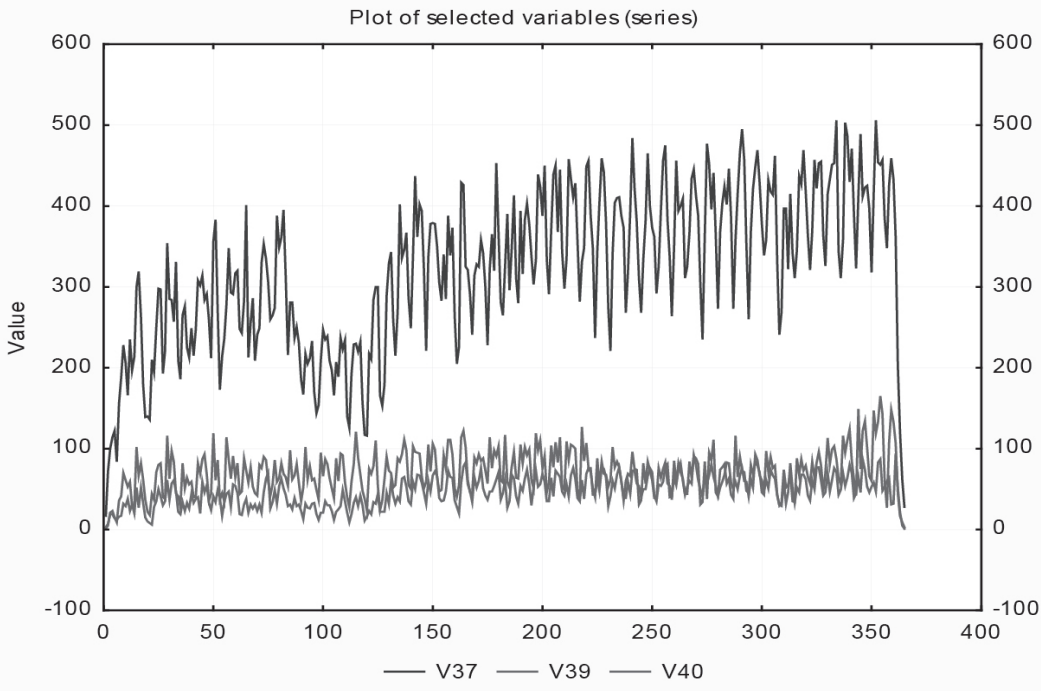

Fig. 5. Time series of transportation volumes 


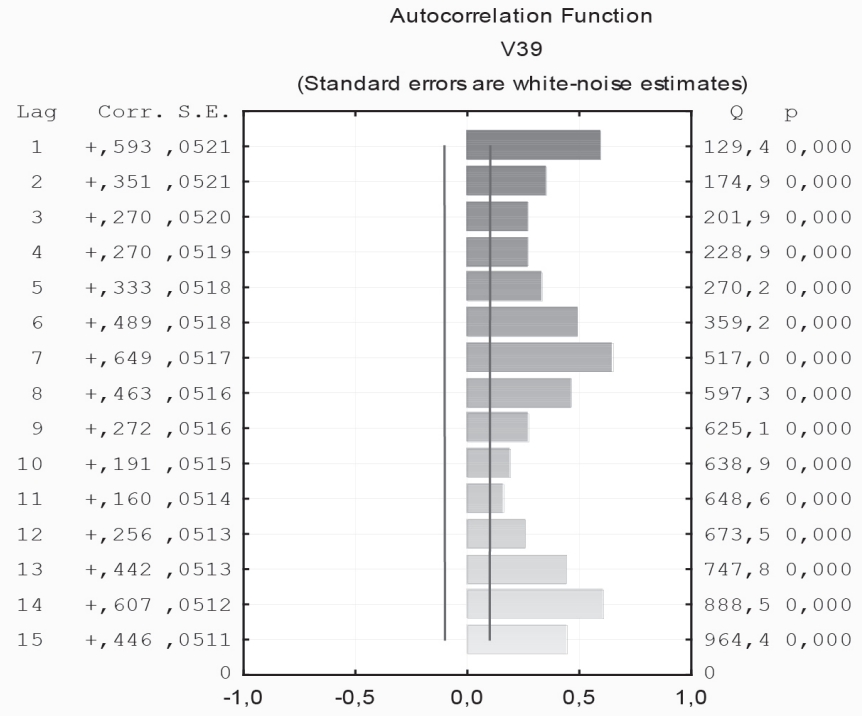

Conf. Limit

Autocorrelation Function

V37

(Standard errors are white-noise estimates)

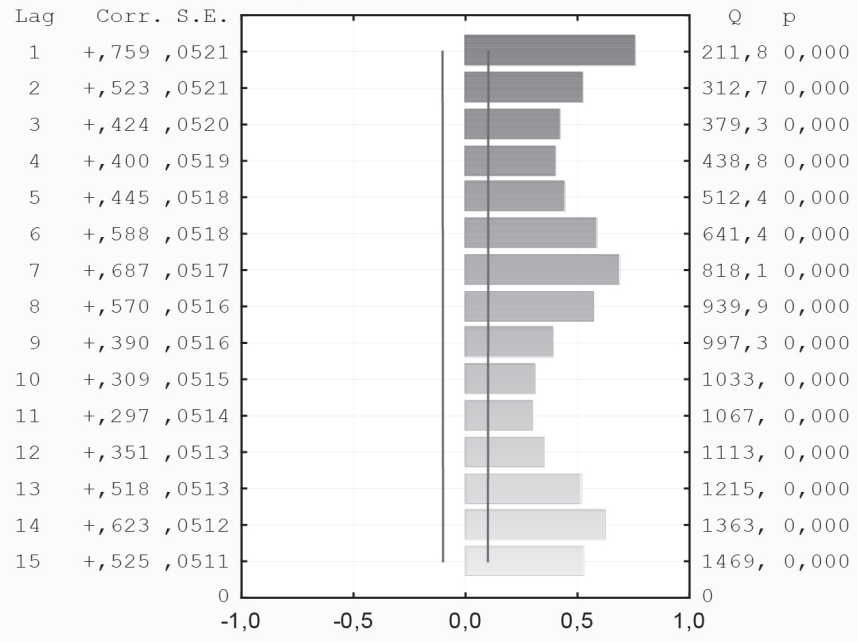

Conf. Limit

Fig. 6. The autocorrelation functions of cargo traffics 
The analysis was conducted for cargo traffics on imports from Europe in three checkpoints. The corresponding graphs are shown in Figure 5.

It should be noted that the autocorrelation functions of flows through point 37 and 39 (Figure 6) have a sufficiently large value, which means the considerable stream inertia.

For a more adequate model of cargo traffic forecast during the work it is proposed to use spectral analysis, which makes it possible to assess the seasonality of the time series [15].

As graphic form of the results visualization the following periodogram is used: $\mathrm{P}_{\mathrm{k}}=\sin (\mathrm{K})_{\mathrm{k}}{ }^{2}+\cos (\mathrm{K})_{\mathrm{k}}{ }^{2 *} \mathrm{~N} / 2$, where $P_{k}$ - the periodogram values obtained at the frequency $v_{\mathrm{k}}$, and $N$ - the total duration of the time series. These values can be interpreted as a variation of the data at a given frequency. When visualizing the periodogram it can be displayed depending on the periods or frequencies.

Constructed periodogram of analysed series of cargo traffics gave quite interesting results.

Thus, for cargo traffic through the point 39 there are three distinct components of seasonality (Figure 7).

The highest amplitude value corresponds to the period of 7 days (week). Similar results were obtained for cargo traffic through the point 37.

However, in this flow two frequencies prevail, namely 7 days, which corresponds to the periodogram value 0.15 , and the frequency corresponding to half weeks is added. There are three prevailing frequency of 7 days, 3.5 days and 2.33 days for cargo traffics. Similar results were obtained for traffic through the point 37 . However, in this flow two frequencies prevail, namely 7 days, which corresponds to 0.15 periodogram. To solve the problem of forecasting cargo traffics as the base model the usage of time series model is proposed: $\mathrm{X}_{\mathrm{t}}=\mathrm{b}+\mathrm{e}_{\mathrm{t}}$, where $b$ - constant and e (epsilon) - random error. Moreover, the decreasing weight is set in the exponential smoothing 
method for more distant observations under exponential law. Unlike the moving average all the values of the time series are taken into account.

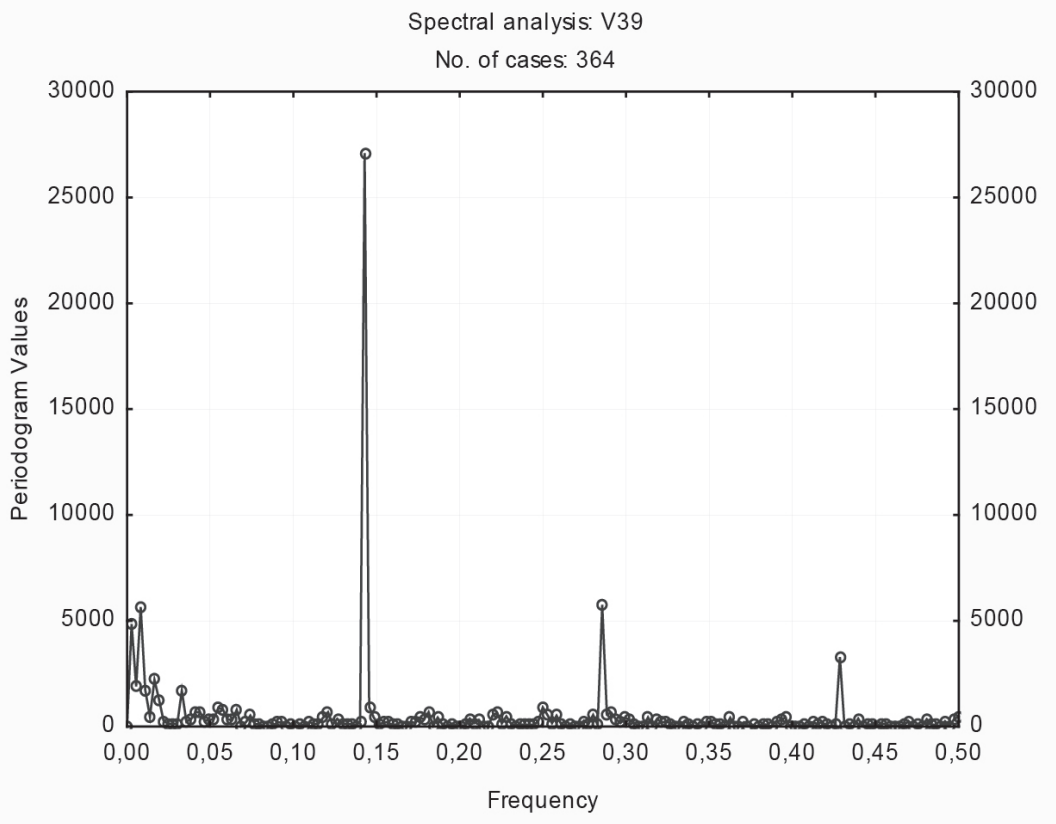

Fig. 7. Cargo traffic periodogram through the 39 point

\section{Conclusion}

It is proposed to implement the cargo traffics simulation through the theory of controlled networks, in which the flow determines how the transfer of some objects will come from one vertex to another on its arcs. The main elements of the network are the source and the drain, which characterize the points of sending and receiving of goods. Control, bandwidth and distribution matrices, which are aimed at a formal problem solution of cargo traffic maximizing, were formed. The process modelling problem of cargo consolidation, which allows 
us to estimate the numerical characteristics of random variables determining cargo traffics, was set and solved.

One of the objectives is to convert the input streams of small volume, which come from shippers on the vans to the output streams, representing the volume of the container as the goods accumulation belonging to the same recipient.

\section{References}

1. Elova I.A., Lebedeva I.A. The integrated logistics systems of delivery of resources: (the theory, methodology, the organization). Minsk: Right and economy, 2011. 460 p.

2. Ivanov D.A. Management of chains of deliveries. St. Petersburg: Publishing house of Polytechnical university, 2010. 659 p.

3. Mirotin L.B., Gudkova V.A., Zyryanov V.V., etc. Management of cargo streams in transport and logistics systems. Under the editorship of L.B. Mirotin. M.: Hot line-Telecom, 2010. 704 p. (Engineering Logistics series).

4. Mirotin L.B., Nekrasov A.G., Gudkova V.A., etc. Increase of efficiency of freight transportation on the basis of creation of steady transport and logistic system of modular type for high-speed processing and cargo delivery: monograph. Under a general edition of L.B. Mirotin and A.G. Nekrasov. M.: Tekhpoligraftsentr, 2013. 232 p. (Engineering Logistics series).

5. Nekrasov A.G., Belyaev V.M., Mirotin L.B., Pokrovsky A.K. Management of processes in transport logistic systems: studies. Grant. Under a general edition of A.G. Nekrasov; MADI. M, 2011. 127 p.

6. Sterligova A.N. Stockpile management in chains of deliveries Moscow: INFRA-M, 2009. 428 p.

7. Tregubov P.G., Prikhodko V.M., Satyshev S.N., Lazarenko A.V. A technique of forecasting of volumes of the international automobile transportation of goods on the main components//the Motor transportation enterprise. 2014. №7. 
8. Tregubov P.G., Prikhodko V.M., Satyshev S.N. Modeling of intermodal transportation of goods on the basis of the operated networks// the MADI Bulletin. 2014. №3(38).

9. Tregubov P.G., Satyshev S. N. Modular approach to formation integrated transport and logistic//Logistic methods of management of the motor transportation enterprise: digest treatise MADI. M, 2012, pp. 20-27.

10. Tregubov P.G. About the concept of creation of transport system of high-speed cargo delivery by passenger flights on the basis of the Moscow air hub//Automation and management in technical systems. 2014. No. 3(1). http://elibrary.ru/item.asp?id=20344649.

11. Tregubov P.G. The organization of the movement of cars tractors with replaceable trailers and semi-trailers//Models and methods of management of processes on transport, in the industry and education: digest treatise MADI. M, 2013, pp. 57-64.

12. Tregubov P.G., Satyshev S.N. Basic principles of formation of micrologistic control systems of the motor transportation enterprise//Logistic methods of management of the motor transportation enterprise: digest treatise MADI. M, 2012, pp. 14-19.

13. Tregubov P.G., Mirotin L.B., Nekrasov A.G., Stepanov P.V. Increase of efficiency of freight transportation on the basis of creation of steady transport and logistic system of modular type for high-speed processing and cargo delivery//the MADI Bulletin. 2013. No. 3(34), pp. 61-65.

14. Tregubov P.G., Nikolaev A.B., Prikhodko V.M., Stroganov V.U. Tools of production and logistics support life cycle of high-tech products // Life Science Journal. 2014. №8.

15. Tregubov P.G. Statistics of transportation of goods on the motor transport//Model and methods of management of processes on transport, in the industry and education: digest treatise MADI. M, 2013, pp. 5-11.

16. Troyanov A.E. Development of strategy of reengineering of the motor transportation enterprise on the basis of the logistic principles. M.: Prosoft-M, 2003. 412 p. 


\section{DATA ABOUT THE AUTHORS}

Nikolaev Andrey Borisovich, Laureate of the Government Prize of the Russian Federation, Honored Worker of Science of the Russian Federation, Dr.Sci.Tech., Professor, Head of the Department

Moscow Automobile and Road Construction State Technical University (MADI)

64, Leningradsky prospekt, 64, Moscow, 125319, Russian Federation

nikolaev.madi@mail.ru

Ivakhnenko Andrey Andreevich, Candidate of Technical Sciences, Associate Professor

Moscow Automobile and Road Construction State Technical University (MADI)

64, Leningradsky prospekt, 64, Moscow, 125319, Russian Federation

jointlab@mail.ru

Pashayev Valid Vakhaewich, Assistant

Grozny State Oil Technical University

100, Ordzhonikidze Str., Grozny, Chechen Republic, 364051, Russian Federation

ranas@rambler.ru

Tregubov Pavel Gennadyevich, Candidate of Technical Sciences, Associate Professor

Moscow Automobile and Road Construction State Technical University (MADI)

64, Leningradsky prospekt, 64, Moscow, 125319, Russian Federation

tpashok@mail.ru 